\title{
UPAYA MENINGKATKAN PENGETAHUAN DAN KETERAMPILAN IBU MENGENAI KESEHATAN GIGI DAN MULUT BALITA
}

\section{EFFORTS TO IMPROVE MATERNAL KNOWLEDGE AND SKILLS ABOUT DENTAL HEALTH OF CHILDREN UNDER FIVE}

\author{
${ }^{1)}$ Anita Rosa Delima, ${ }^{2)}$ Nugroho Ahmad Riyadi, ${ }^{3)}$ Chaerita Maulani \\ ${ }^{1,2,3)}$ Program Studi Kedokteran Gigi, Fakultas Kedokteran, Universitas YARSI, \\ Jln Letjen Suprapto Cempaka Putih Jakarta Pusat Telp 021-4244574, email :anita.rosa@yarsi.ac.id; \\ nugroho.ahmad@yarsi.ac.id;chaerita.maulani@yarsi.ac.id
}

\begin{abstract}
ABSTRAK
Pengetahuan ibu merupakan faktor penting dalam kesehatan balita, hal ini karena ibu berpengaruh terhadap proses pendidikan anak sejak dini. Orang tua, terutama ibu perlu membiasakan anak balitanya untuk menjaga kebersihan mulut dengan menggosok gigi secara teratur. Kebersihan dan kesehatan gigi sulung seringkali kurang mendapatkan perhatian dari orang tua, hal ini karena anggapan bahwa kerusakan pada gigi sulung bukan merupakan suatu masalah dan tidak memerlukan perawatan karena akan digantikan oleh gigi permanen. Kegiatan pengabdian masyarakat ini bertujuan untuk meningkatkan pengetahuan serta keterampilan para ibu di RPTRA Harapan Mulia mengenai kesehatan gigi dan mulut balita. Sebelum kegiatan ini dilaksanakan, dilakukan pembuatan buku panduan yang berisi materi mengenai tumbuh kembang gigi pada anak, ciri gigi sehat, diet sehat serta cara pemeliharaan kesehatan gigi dan mulut balita. Metodeyang dilakukanadalahmelakukan penyuluhan mengenai kesehatan gigi dan mulut balita, pelatihan keterampilan menyikat gigi, permainan untuk balita. Sebelum dilakukan penyuluhan, dilakukan pre testterlebih dahulu untuk menilai pengetahuan awal para ibu mengenai kriteria gigi sehat, cara pemeliharaan kebersihan rongga mulut balita, serta diet sehat. Setelah diberikan penyuluhan dan pelatihan dilakukan post test dengan soal yang sama. Hasil dari kegiatan ini ialah adanya adanya peningkatan pengetahuan pada $100 \%$ peserta dari target $70 \%$, serta $70 \%$ peserta lulus uji keterampilan tentang cara menyikat gigi. Diharapkan dengan meningkatnya pengetahuan dan keterampilan ibu dapat diaplikasikan dalam kehidupan sehari-hari sehingga dapat meningkatkan kesehatan gigi dan mulut balita di RPTRA Harapan Mulia.Sebagai kelanjutan dari kegiatan pengabdian masyarakat ini diharapkan dapat dilakukan evaluasi kembali mengenai tingkat pengetahuan dan keterampilan ibu, serta dapat dilakukanpembuatan video edukasi yang berisi caracara pemeliharaan kesehatan gigi dan mulut balita.
\end{abstract}

\section{Kata Kunci : Pengetahuan, Keterampilan, Ibu, Kesehatan Gigi dan Mulut Balit}

\section{ABSTRACT}

Maternal knowledge is an important factor in the health of children under five, this is because the mother affects the child's education process from an early age. Parents, especially mothers need to familiarize their toddlers to maintain oral hygiene by brushing teeth regularly. The health of deciduous teeth often get less attention from parents, this is because the assumption that the damage to the deciduous teeth is not a problem and does not require treatment because it will be replaced by permanent teeth.This community service activity is aimed to improve the knowledge and skills of the mothers in RPTRA Harapan Muliaabout the dental health of children under five. The methods undertaken in this activity are the counseling, skills training on how to brush their teeth, education games for toddler, and distribution of guidance book on maintaining dental and oral health of toddlers. Before the counseling, pre-tested first to assess the mother's initial knowledge about the criteria of healthy teeth, how to maintain oral hygiene, and healthy diet. After being given counseling and training, post test was carried out with the same questions. The result of this activity is the increase of knowledge on $100 \%$ of participants from the target of $70 \%$, and $70 \%$ of participants passed the skill test on how to brush their teeth. It is expected that with the increasing of mother's knowledge and skill can be applied in everyday life so as to improve dental and toddler's 
health in RPTRA Harapan Mulia. As a continuation of community service activity is expected to be reevaluated about the level of knowledge and skills of mothers, and can be made of educational videos that contain ways of maintaining oral health of children under five.

Keywords: Knowledge, Skills, Mother, Dental health of children under five

Submitted : 19 Maret $2018 \quad$ Revision : 29 Juli $2018 \quad$ Accepted : 31 Juli 2018

\section{PENDAHULUAN}

Pengetahuan ibu merupakan faktor penting dalam kesehatan balita, hal ini karena ibu berpengaruh terhadap proses pendidikan anak sejak dini. Orang tua, terutama ibu perlu membiasakan anak balitanya untuk menjaga kebersihan mulut dengan menggosok gigi secara teratur. karena umumnya anak lebih banyak menghabiskan waktunya bersama ibu. Umumnya, anak lebih banyak menghabiskan waktunya bersama ibu sehingga ibu dianggap dapat melakukan pendekatan yang tepat untuk membiasakan anak memelihara kesehatan gigi dan mulut (Solikin, 2013).

Kesehatan gigi susu seringkali diabaikan oleh orangtua karena dianggap hanya bersifat sementara dan akan digantikan oleh gigi tetap. Pada kenyataannya, gigi susu berperan penting dalam kemampuan berbicara sekaligus proses pengunyahan yang berdampak pada nutrisi dan tumbuh kembang anak. Selain itu, gigi susu juga berfungsi sebagai paduan bagi pertumbuhan gigi tetap.

Pertumbuhan dan perkembangan gigi sulung terjadi sejak awal usia janin,dilanjutkan setelah bayi lahir, anak bertambah besar, dan memasuki periode remaja dan dewasa. Seiring dengan pertmubuhan tubuh secaraumum, terjadi pergantian periode gigi sulung menjadi gigi permanen.

Proses tumbuh kembang dipengaruhi oleh berbagai eksternal dan internal. Secara biologis,aspek internal mencakup faktor genetik, penyakit infeksi dan hormonal, aspek eksternal berupagizi, dan sosiodemografi. Penyimpangan dan gangguan pada berbagai aspek tersebut akanmengakibatkan kelainan/anomali tumbuh kembang tubuh baik secara umum dan gigi secarakhusus.
Karies gigi pada anak merupakan masalah serius dalam kesehatan gigi dan mulut di indonesia dengan prevalensi hingga 90,05\% (Asmawati \& Pasolon, 2007). Menurut data Riset Kesehatan Dasar (RISKESDAS) tahun 2013 dari Departemen Kesehatan Republik Indonesia menunjukkan sebanyak 25,9\% penduduk Indonesia mengalami masalah kesehatan gigi dan mulut, dan 10,4 \% diantaranya balita (Badan Penelitian Dan Pengembangan Kesehatan Kementerian Kesehatan RI, 2013).

Ruang Publik Terpadu Ramah Anak (RPTRA) adalah tempat dan/atau ruang terbuka yang memadukan kegiatan dan aktivitas warga dengan mengimplementasikan 10 (sepuluh) program Pokok Pemberdayaan dan Kesejahteraan Keluarga untuk mengintegrasikan dengan program Kota Layak Anak. Tujuan RPTRA dibangun antara lain untuk menyediakan ruang terbuka untuk memenuhi hak anak agar anak dapat hidup, tumbuh, berkembang dan berpartisipasi secara optimal sesuai dengan harkat dan martabat kemanusiaan, menyediakan prasarana dan sarana kemitraan antara Pemerintah Daerah dan masyarakat dalam memenuhi hak anak dan menyediakan prasarana dan sarana kota sebagai Kota Layak Anak (Pemerintah Daerah Khusus Ibukota Provinsi DKI Jakarta, 2015)

RPTRA Harapan Mulia berlokasi di Kemayoran, Jakarta Pusat dan diresmikan pada tahun 2016. RPTRA ini memiliki luas 3446 meter persegi dan dilengkapi dengan ruang sera guna, perpustakaan, lapangan basket, futsal, kolam gizi, tanaman obat keluarga, area bermain anak, ruang laktasi serta toilet untuk difabel. RPTRA in memiliki beberapa fungsi, salah satu diantaranya ialah sebagai prasarana dan sarana kegiatan sosial 
termasuk didalamnya untuk pengembangan pengetahuan dan keterampilan

\section{Secara fisik, kondisi RPTRA} Harapan Mulia saat ini sudah sangat baik karena dilengkapi dengan beberapa fasilitas yang masih terpelihara dengan baik.Nilai keunggulan dari RPTRA Harapan Mulia ialah banyaknya kegiatan yang dilakukan di RPTRA tersebut dalam dalam penyuluhan dan pelatihan untuk meningkatkan pengetahuan dan keterampilan warga.

Salah satu kegiatan RPTRA ialah diadakannya pelatihan dan penyuluhan dalam rangka pengembangan pengetahuan dan keterampilan. Meskipun sudah beberapa kali diadakan penyuluhan dan pelatihan yang berkaitan dengan pemeliharaan kesehatan, namun belum pernah ada topik mengenai kesehatan gigi dan mulut balita.

Karies gigi merupakan penyakit yang banyak menyerang anak-anak maupun dewasa.Data dari Persatuan Dokter Gigi Indonesia menyebutkan bahwa sedikitnya $89 \%$ penderita karies adalah anakanak.RISKESDAS menyebutkan prevalensi nasional masalah gigi dan mulut dijumpai sebesar 25.9\%.Provinsi DKI Jakarta memiliki prevalensi masalah gigi dan mulut diatas angka nasional yaitu 29.1\%(Riset Kesehatan Dasar Departemen Kesehatan, 2013).

Kesehatan gigi susu seringkali diabaikan oleh orangtua karena dianggap hanya bersifat sementara dan akan digantikan oleh gigi tetap. Pada kenyataannya, gigi susu berperan penting dalam kemampuan berbiara sekaligus proses pengunyahan yang berdampak pada nutrisi dan tumbuh kembang anak. Selain itu, gigi susu juga berfungsi sebagai paduan bagi pertumbuhan gigi tetap.

Pengetahuan seorang ibu merupakan hal penting dalam menjaga kesehatan balitanya karena ibu berpengaruh terhadap proses pendidikan anak sejak dini. Orang tua, terutama ibu perlu membiasakan anak balitanya untuk menjaga kebersihan mulut dengan menggosok gigi secara teratur, karena umumnya anak lebih banyak menghabiskan waktunya bersama ibu. Ibu dianggap lebih mengerti keadaan anak-anaknya, sehingga dapat melakukan pendekatan yang tepat untuk membiasakan anak mememihara kesehatan gigi dan mulut.

\section{METODE KEGIATAN}

Metode yang dilakukan pada kegiatan ini adalah melakukan penyuluhan mengenai kesehatan gigi dan mulut balita, pelatihan keterampilan menyikat gigi, permainan untuk balita.Kegiatan ini melibatkan mitra yaitu pengurus RPTRA Harapan mulia dan ibu-ibu di Harapan Mulia yang memiliki anak usia balitai. Sebelum dilakukan kegiatan, pelaksana meminta izin penyelenggaraan kepada pengurus RPTRA Harapan Mulia dan medapatkan sambutan yang positif untuk melaksanakan kegiatan tersebut. Bantuan yang diberikan oleh mitra adalah penyediaan tempat, fasilitas komputer dan perangkat audio serta sosialisasi undangan kepada para ibu yang memiliki anak usia balita. Sarana dan alat yang dipersiapkan oleh pelaksana adalah buku panduan pemeliharaan kesehatan gigi dan mulut balita dan check list keterampilan menyikat gigi, manekin gigi, sikat gigi, dan games pemilihan diet sehat untuk balita (gambar 1). Penyusunan buku panduan dilakukan sebelum kegiatan ini dilaksanakan. Materi yang tertulis dalam buku ini ialah mengenai tumbuh kembang gigi pada anak, ciri gigi sehat, diet sehat serta cara pemeliharaan kesehatan gigi dan mulut balita. Waktu dan tempat kegiatan dapat dilihat pada tabel dibawah ini :

Tabel 1. Jadwal dan Lokasi Kegiatan

\begin{tabular}{|c|c|c|}
\hline Kegiatan & Waktu & Tempat \\
\hline $\begin{array}{l}\text { Penyusunan buku } \\
\text { panduan } \\
\text { pemeliharaan } \\
\text { kesehatan gigi } \\
\text { dan mulut balita }\end{array}$ & $\begin{array}{lr}\text { Mg } & \mathrm{Ke}-3-4 \\
\text { dan } & 2 \\
\text { Desember } \\
2017\end{array}$ & $\begin{array}{l}\text { Prodi } \\
\text { Kedokteran } \\
\text { Gigi } \quad \text { FK } \\
\text { YARSI }\end{array}$ \\
\hline $\begin{array}{l}\text { Penyusunan } \\
\text { check list } \\
\text { keterampilan } \\
\text { untuk menyiikat } \\
\text { gigi }\end{array}$ & $\begin{array}{l}\mathrm{Mg} \text { ke } 1-2 \\
\text { Januari } 2018\end{array}$ & $\begin{array}{l}\text { Prodi } \\
\text { Kedokteran } \\
\text { Gigi } \quad \text { FK } \\
\text { YARSI }\end{array}$ \\
\hline
\end{tabular}




\begin{tabular}{|c|c|c|}
\hline $\begin{array}{l}\text { Pelatihan } \\
\text { pengetahuan dan } \\
\text { keterampilan ibu } \\
\text { mengenai } \\
\text { kesehatan gigi } \\
\text { dan mulut balita }\end{array}$ & $\begin{array}{ll}24 & \text { Januari } \\
2018 & \end{array}$ & $\begin{array}{l}\text { RPTRA } \\
\text { Harapan Mulia }\end{array}$ \\
\hline
\end{tabular}

Evaluasi kegiatan ini dengan melakukan pre dan post sebelum dan selesai pelatihan untuk evaluasi peningkatan pengetahuan dan uji keterampilan dengan menggunakan check list. Rencana untuk kegiatan pengabdian masyarakat selanjutnya untuk melakukan evaluasi kembali mengenai tingkat pengetahuan dan keterampilan ibu serta diharapkan dapat dilakukan pembuatan video panduan pemeliharan kesehatan gigi dan mulut balita.

\section{HASIL DAN PEMBAHASAN}

Hasil dari kegiatan penyuluhan dan pelatihan keterampilan ini adalah sebagai berikut:

1. Meningkatnya pengetahuan ibu mengenai tumbuh kembang gigi baita. Pertanyaan yang diberikan ialah mengenai lapisan gigi, jenis gigi sulung dan jumlah gigi tetap. Pada pre test hanya $50 \%$ yang menjawab benar dan setelah post test $80 \%$ ibu menjawab benar.

Masa balita merupakan periode penting dalam proses tumbuh kembang manusia dan menjadi penentu keberhasilan pertumbuhan dan perkembangan anak di periode selanjutnya. Masa ini merupakan masa yang berlangsung cepat dan tidak akan pernah terulang, sehingga sering disebut golden age atau masa keemasan (Ayuningtiyas, 2013).

Pertumbuhan dan perkembangan gigi sulung terjadi sejak awal usia janin,dilanjutkan setelah bayi lahir, anak bertambah besar, dan memasuki periode remaja dan dewasa. Seiring dengan pertmubuhan tubuh secaraumum, terjadi pergantian periode gigi sulung menjadi gigi permanen. Pada saat bayi berusia 6-9 bulan, dua gigi seri rahang bawah akan erupsi/tumbuh yang diikuti dengan gigi seri rahang atas. Pada usia 7-10 bulan tumbuh dua gigi seri depan kedua rahang atas maupun rahang bawah. Kadang gigi seri kedua di rahang bawah tumbuh lebih dulu sebelum rahang atas. Kemudian satu gigi geraham depan tumbuh pada usia 16-20 bulan. Gigi taring juga mulai muncul pada usia yang sama. Gigi geraham kedua tumbuh pada usia 23-30 bulan. Rata-rata anak akan mempunyai gigi susu lengkap (20) pada usia 3 tahun (Anonim, 2017)

2. Meningkatnya pengetahuan ibu mengenai cara pemeliharaan kesehatan gigi dan mulut pada balita.tumbuh kembang gigi baita. Pertanyaan yang diberikan ialah mengenai apa penyebab gigi sakit gigi pada anak, frekuensi menyikat gigi, waktu menyikat gigi, penggunaan pasta gigi. Pada pre test hanya $40 \%$ yang menjawab benar dan setelah post test $70 \%$ ibu menjawab benar.

Membersihkan gigi anak dapat dilakukan dengan penyikatan gigi yang bertujuan untuk menghilangkan plak. Anak diatas 2 tahun sudah dapat mulai diajarkan cara menyikat gigi dengan memberikan contoh secara berulang- ulang agar anak teratur mengikutinya. Metode yang bisa diajarkan pada usia ini adalah metode Schrobm karenasangat mudah dan sederhana untuk diajarkan kepada anak. Caranya ialah menyikat gigi bagian atas dan bawah dengan arah kesamping kanan dan kiri, kemudian seluruh gigi bagian samping dan seluruh gigi bagian belakang disikat, lalu anak berkumur dengan air bersih beberapa kali. Waktu menyikat gigi sebaiknya dilakukan teratur minimal 2 kali sehari yaitu pagi setelah sarapan dan malam sebelum tidur. Untuk menyikat gigi yang benar sebaiknya dilakukan selama lebih dari 2 menit, walau demikian, yang terpenting bukan lamanya waktu dalam menyikat gigi, tetapi pembersihan gigi itu sendiri dari plak (Santrock, 2007).

Pemilihan sikat gigi pada anak balita sebaiknya dipilih sikat gigi yang ukurannya kecil dengan tangkai yang mudah digenggam.Pilihlah bulu sikat yang halus dengan bagian kepala sikat menyempit agar mudah menjangkau bagian dalam rongga mulut. Anak usia 1-5 tahun bisa memakai sikat dengan 3 deret bulu. American Dental Association menganjurkan ukuran maksimal kepala sikat gigi balita adalah $18 \times 7 \mathrm{~mm}$. Apabila bulu sikat gigi sudah tidak beraturan 
atau mekar maka harus segera diganti karena dapat melukai gusi (Budiman, 1996).

3. Meningkatnya pengetahuan ibu mengenai pemilihan diet sehat.Pertanyaan yang diberikan ialah mengenai jenis makanan apa yang baik untuk anak. Pada pre test hanya $40 \%$ yang menjawab benar dan setelah post test $80 \%$ ibu menjawab benar.

Pola makan dan kebiasaan membersihkan gigi menentukan status kesehatan gigi dan mulutnya. Anak yang terbiasa mengkonsumsi makanan manis diluar jam makan akan meningkatkan resiko karies. Makanan dan minuman manis yang tinggi gula seperti biskuit, coklat, permen, kue, susu dan cemilancemilan dapat berbahaya bagi kesehatan gigi. Frekuensi pemberian makanan manis yang sering atau diluar jam makan ini dapat meningkatkan resiko terjadinya karies pada anak. Keadaan ini diperburuk dengan anak yang malas untuk menyikat gigi(Varseo, 1999).

4. Meningkatnya keterampilan ibu mengenai cara menyikat gigi yang benar. Setelah dilakukan pelatihan, dilakukan pengujian keterampilan ibu dan hasilnya $100 \%$ ibu dapat menyikat gigi dengan cara yang benar.

Sebelum dilakukan pelatihan keterampilan cara menyikat gigi peserta diberi pengetahuan tentang cara menyikat gigi yang benar, pemilihan pasta gigi dan sikat gigi. Peningkatan pengetahuan tentang menyikat gigi ini penting untuk meningkatkan keterampilan kader dalam menyikat gigi yang benar. Menyikat gigi merupakan cara pemeliharan kesehatan gigi dan mulut yang paling efektif. Akan tetapi ada beberapa hal yang harus menjadi perhatian yaitu teknik menyikat gigi, waktu menyikat gigi, serta pemilihan sikat dan pasta gigi yang benar.Pelatihan dibuat dengan sederhana yaitu menggunakan manekin gigi dan sikat gigi. Para peserta diminta memperagakan cara menyikat gigi dengan teknik yang benar.

Target pada pelatihan ini adalah $70 \%$ peserta lulus uji keterampilan. Hasilnya seluruh peserta (100\%) peserta lulus uji keterampilan. Salah satu keterbatasan pada sesi keterampilan ini adalah waktu yang terbatas sehingga pelatihan keterampilan dilakukan sedikit terburu-buru. Untuk itu masih diperlukan pelatihan keterampilan kembali oleh kader kesehatan di RPTRA Harapan Mulia dan pembuatan video edukasi agar para ibu tetap bisa melakukan keterampilan cara menyikat gigi dengan benar.

Para ibu sangat antusias saat pemberian materi, hal ini diketahui dari banyaknya pertanyaan yang diajukan mengenai pemeliharan kesehatan gigi dan mulut balita. Evaluasi peningkatan pengetahuan tentang isi buku panduan dilakukan dengan membandingkan nilai pre dan post test. Hasil pretest rata-rata nilai 45 . Hasil postest rata-rata 75 . Targetnya adalah peningkatan pengetahuan pada $70 \%$ peserta. Hasil evaluasi semua peserta mengalami peningkatan nilai postest (100\%). Diharapkan dengan peningkatan pengetahuan ini dapat menjadi bekal yang baik untuk meningkatkan keterampilan kader poskestren dalam penanganan kedaruratan gigi.

Teori Lawrence W. Green mengatakan bahwa pengetahuan merupakan faktor pemicu dalam perubahan perilaku. Pada dasarnya perilaku seseorang dipengaruhi oleh pengetahuannya akan sesuatu hal. Pengetahuan atau kognitif merupakan domain yang sangat penting untuk terbentuknya tindakan seseorang.Apabila suatu tindakan didasari oleh pengetahuan maka perilaku tersebut akan bersifat langgeng (long lasting), sebaliknya apabila perilaku tersebut tidak didasari oleh pengetahuan dan kesadaran maka perilaku tidak akan berlangsung lama (Notoadmodjo, 2003)

\section{SIMPULAN}

Hasil kegiatan menunjukkan ada peningkatan pengetahuan tentang pemeliharaan kesehatan gigi dan mulut balita pada $100 \%$ peserta. Terdapat peningkatan keterampilan ibu dalam meyikat gigi $(100 \%)$. 


\section{DAFTAR PUSTAKA}

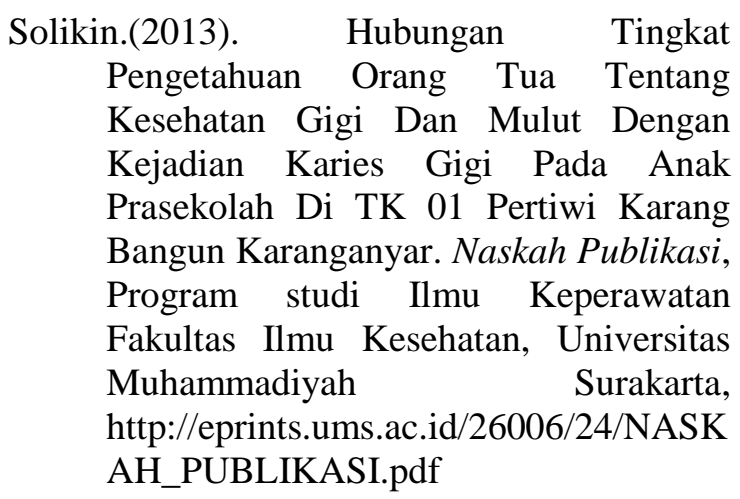

Asmawati, A., Pasolon, F. (2007). Analisis Hubungan Karies Gigi Dan Status Gizi Anak Usia 10-11 Tahun Di SD Athirah, SDN 1 Bawakaraeng Dan SDN 3 Bangkala. Journal of Dentomaxillofacial Science, 6 (2), 78-84.

Badan Penelitian Dan Pengembangan Kesehatan Kementerian Kesehatan Ri. (2013), Riset Kesehatan Dasar. http://www.depkes.go.id/resources/do wnload/general/Hasil\%20Riskesdas\% 202013.pdf

Pemerintah Daerah Khusus Ibukota Provinsi DKI Jakarta. Pergub No.196 Tahun 2015 tentang Pedoman Pengelolaan RPTRA.

Ayuningtiyas LW. (2013). Hubungan Pelaksanaan Fungsi Keperawatan Kesehatan Keluarga Dengan Pencapaian Tugas Perkembangan Balita Di Bina Keluarga Balita (BKB) Glagawero Kecamatan Kalisat. Skripsi, Jember: Program studi ilmu keperawatan Universitas Negeri Jember.

Anonim, (2017), Art of Pediatric Dentistry. Eruption of Your Child's Teeth. Diakses pada 11 April 2017 pada http://www.artofpd.com

Santrock. J.W., (2007). Perkembangan Anak Jilid 2, (terjemahan), Jakarta: Erlangga.
Budiman JA. (1996). Mengenal Gigi Anda, Petunjuk Pada Orang Tua. Jakarta: Arcan.

Varseo S. (1999). Caries-Preventive Treatment Approaches For Child And Youth At Two Extremes Of Dental Health In Helsinki, Finland. Academic Dissertation. Finland: University of Helsinki.

Notoadmodjo S. 2003). Pendidikan Dan Perilaku Kesehatan. Jakarta: PT Rineka Cipta. 